\title{
Analysis of the Supply-demand Value Chain in the B2B E-business
}

\author{
Guoliang Ge \\ Department of Information Management, HuaZhong Normal University, \\ Wuhan 430079, China \\ geguolian70@163. com
}

\begin{abstract}
Value chain is a basic method and framework to understand enterprise behavior and guide competition conduct. In the B2B E-business, traditional value chain changes greatly under the influence of information technology. So, in the paper, B2B E-business's influence on traditional value chain was analyzed, and similarities and differences between physics value chain and virtual value chain are compared. The relationship of participate partners in the transfer process of virtual value chain was investigated using collaboration-deal model. At the base of that, the model of enterprise value network based on value chain integration and transfer process was established. Finally, IPR-PN model based on Petri network was established, which achieved the simulation of value chain transfer.
\end{abstract}

\section{Introduction}

Business deal of business to business (B2B) and that of business to consumer (B2C) via network are called E-business. From the latter half of 1999, upsurge of Ebusiness occurred in USA, which is called the third phase of network industry, it is a real E-business epoch. In 2005, the gross of E-business deal was 49000 hundred million dollar; in 2006, the gross reached about 99000 hundred million dollar, which showed a promising foreground. So, the task of studying B2B E-business, helping enterprise find the field that can impel value increment by value chain analysis methods, and exploring the integration approach of "Click+Brick" is pressing.

Professor Porter in the book- competition advantage proposed the conception of value chain, which provided a basic method and framework to understand the enterprise behavior and guide competition. To analyze the cost and value of business deal in different phase, Porter distinguished business deal into the basic and assistant deal, which was designed into framework of value chain analysis.

Value chain is employed to support common stratagem analysis, at the same time, it is a efficient tool for information systems management; which can help system

Please wse the following format when citing this chapter:

Ge, G., 2007, in IIIP International Federation for Information Processing, Volume 251, Integration and Innovation Orient to F-Society Volumel, Wang, W. (Eds), (Boston: Springer), pp. 80-87. 
development staff identify information technology that brought the enterprise strategic chance [2-3]. With the advent of E-business, value depends greatly on the data, information, knowledge and so forth. Virtual value chain becomes the tool that analyzes the change E-business brings in enterprise management. The application of value chain model in information system was extended into virtual value chain [4-6], as a result, the study on value chain also developed into virtual value chain from the physical value chain. In the virtual value chain, the value is not only achieved by physical value of real product, but also information.

Understanding the influence information technology brings on the value chain, modifying physical value chain to exert potential of information technology greatly will promote to achieve the E-business further [7-8]. The phenomenon was regarded in developed countries universally.

\section{Influence of B2B E-business on traditional value chain}

Porter's value chain model can be considered as a typical value chain model, which includes nine kinds of enterprise business. The business deal can be distinguished into basic and assistant deal. The model of value chain can be expressed in figure 1 .

\begin{tabular}{|c|c|c|c|c|c|}
\hline \multirow{4}{*}{$\begin{array}{l}\text { Assistant } \\
\text { action }\end{array}$} & \multicolumn{5}{|c|}{ Infrastructure of enterprise } \\
\hline & \multicolumn{5}{|c|}{ Manpower resource management } \\
\hline & \multicolumn{5}{|c|}{ Technology developme nt } \\
\hline & \multicolumn{5}{|c|}{ Purchase } \\
\hline $\begin{array}{l}\text { Basis } \\
\text { action }\end{array}$ & $\begin{array}{l}\text { Purchase } \\
\text { logistics }\end{array}$ & Produce & $\begin{array}{l}\text { Consignment } \\
\text { logistic }\end{array}$ & $\begin{array}{c}\text { Market } \\
\text { distribution }\end{array}$ & Service \\
\hline
\end{tabular}

Fig.1 Porter's value chain model

Porter's model aims at manufacture enterprise. Value deal focus on the materiel flow, for example, acquirement of raw materials, manufacture, distribution, installation and so on. In B2B E-business, the enterprise achieves the business deal via electronical means. B2B E-business brings the enterprise some influences, they are: (1) changing the traditional approach of stocking, distribution and after service; (2) altering the produce manner and bringing traditional industry revolution; (3) shortening the tach of value chain; (4) innovating the value.

The influence the B2B E-business brings on basic and assistant action of traditional value chain was described in table 1.

Table1 Influence of B2B E-business on basic and assistant action of traditional value chain 


\begin{tabular}{|c|c|}
\hline Action & Influence of B2B E-business \\
\hline Stock logistics & Relation with provider is fast, cheap, credible \\
\hline Produce logistics & $\begin{array}{c}\text { Increasing the relation in enterprise; promoting } \\
\text { clients to participate in produce; responding to change } \\
\text { fleetly }\end{array}$ \\
\hline $\begin{array}{l}\text { Consignment } \\
\text { logistic }\end{array}$ & Relation with clients is fast, cheap, credible \\
\hline $\begin{array}{r}\text { Market } \\
\text { distribution }\end{array}$ & $\begin{array}{l}\text { Decreasing cost, developing market, closing further } \\
\text { with clients }\end{array}$ \\
\hline Service & $\begin{array}{l}\text { Fast and cheap service; more relation channel with } \\
\text { clients, stable clients }\end{array}$ \\
\hline $\begin{array}{r}\text { Enterprise } \\
\text { infrastructure }\end{array}$ & $\begin{array}{l}\text { Oblate Organization Structure, gradual } \\
\text { disappearance of intermediation, the whole } \\
\text { organization became external oriented }\end{array}$ \\
\hline $\begin{array}{l}\text { Manpower } \\
\text { resource } \\
\text { management }\end{array}$ & Internet cultivation and tool of employment \\
\hline $\begin{array}{l}\text { Technology } \\
\text { development }\end{array}$ & $\begin{array}{l}\text { Relating with other enterprises, sharing } \\
\text { information, cooperating each other expediently }\end{array}$ \\
\hline Stocking & Fast, cheap, comprehensive, small cost \\
\hline
\end{tabular}

The influence of B2B E-business on enterprise not only embodies on each business deal ,but also the followings: (1) helping enterprise understand client adequately, (), and providing individuation service; (2) improving the capability that enterprise understands clients, and fidelity of clients. (3) breaching the time-space limit for client to achieve economic profit. So, B2B E-business affects different business deal in value chain; and alters the inner action in enterprise and the coupling relation in different enterprise deals; as a result, it is difficult to adopt traditional value chain model to describe comprehensively the enterprise behavior under Ebusiness environment. Virtual value chain consummates the ability that the traditional value chain explains the created value in an enterprise, and offers a new strategical creation.

\section{Virtual value chain}

\subsection{Connotation of virtual value chain}

Rayport and Sviokla presented the concept of virtual value chain in 1995[6]. Any enterprise competes each other in two different worlds: one of the worlds is a real world that manager can look and feel. The other is a virtual world that information forms, which creates the E-business that creates new value. The new information world is called "market space". The two worlds develop value creation action via different value chain. The foregoing creates value by physical value chain, for example, stocking, product, distribution and so on. The latter creates value by virtual 
value chain, for example, collection of information, organization, integration, choice and so on.

It is necessary to analyze market for understanding the virtual value chain further. A market holds three parts: principal part (surrogate), product and process. Principal part of market is purchaser, bargainor, agency, and other groups (for example, government, protection organization of consumer); product is the exchanged materials; the exchange between the market principal part and other market organization is called process, which includes choice of product, produce, market research, inquirement, order, payment and consumption. The three parts may be real (off-line) and digital (on-line). The range physical value chain and virtual value chain work in marker can be expressed in figure 2 .

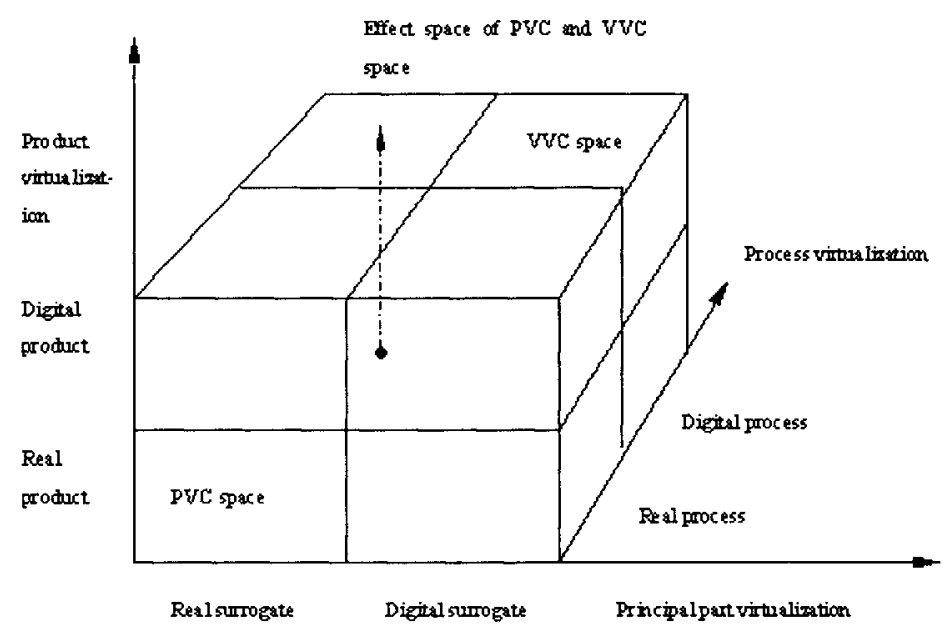

Fig. 2 Effect space of PVC and VVC

Analyzing figure 2, it can be found that virtual value chain is a result of product virtualization, principal part virtualization, process virtualization; furthermore, the effect range of virtual value chain will increase with the increment of digitalization of product, principal part, process.

\subsection{Comparison between virtual value chain and physical value chain}

From figure 2, we can find that virtual value chain and physical value chain have a lot of differences on product, principal part, and process. To understand distinctly the characteristic of virtual value chain, table 2 compared their characteristics from the aspects such as economy principle, management content, process of value increment, information effect and so on.

Table2. Comparison between virtual value chain and physical value chain

\begin{tabular}{|c|c|c|}
\hline Comparison item & Physical value chain & Virtual value chain \\
\hline Economy principle & $\begin{array}{c}\text { Degression of } \\
\text { marginal profit }\end{array}$ & $\begin{array}{c}\text { Increase of marginal } \\
\text { profit }\end{array}$ \\
\hline
\end{tabular}




\begin{tabular}{|c|c|c|}
\hline $\begin{array}{c}\text { Management content } \\
\text { Process of value } \\
\text { increment }\end{array}$ & Real product & $\begin{array}{c}\text { Digital product } \\
\text { Action is continuous } \\
\text { continuous }\end{array}$ \\
\hline Anformation effect & Assistant factors & Creation of value \\
\hline Role of clients & Physical agency & $\begin{array}{c}\text { Degression of } \\
\text { traditional agency, rise } \\
\text { of information agency }\end{array}$ \\
\hline Focus & $\begin{array}{c}\text { Accepter of product } \\
\text { and the sensed kernel } \\
\text { value }\end{array}$ & $\begin{array}{c}\text { Participator of } \\
\text { producing }\end{array}$ \\
\hline
\end{tabular}

\section{Transfer from physical value chain to virtual value chain}

B2B E-business is developing rapidly, the range that digital product refers is expanding, and various information agency is developing vigorously. With the development of informationlization, information technology is adopted more and more widely in process of enterprise operation, the status of virtual value chain is becoming more and more important in value creation. Therefore, some problems refer to the transfer process from physical value chain to virtual value chain are showed. Of course, the transfer is not unrestrained; it is reason is that any E-business under healthy operation condition depends on the balance between virtual value chain and physical value chain. Application of B2B E-business is expending, the transfer from physical value chain to virtual value chain can be expressed into figure 3 .

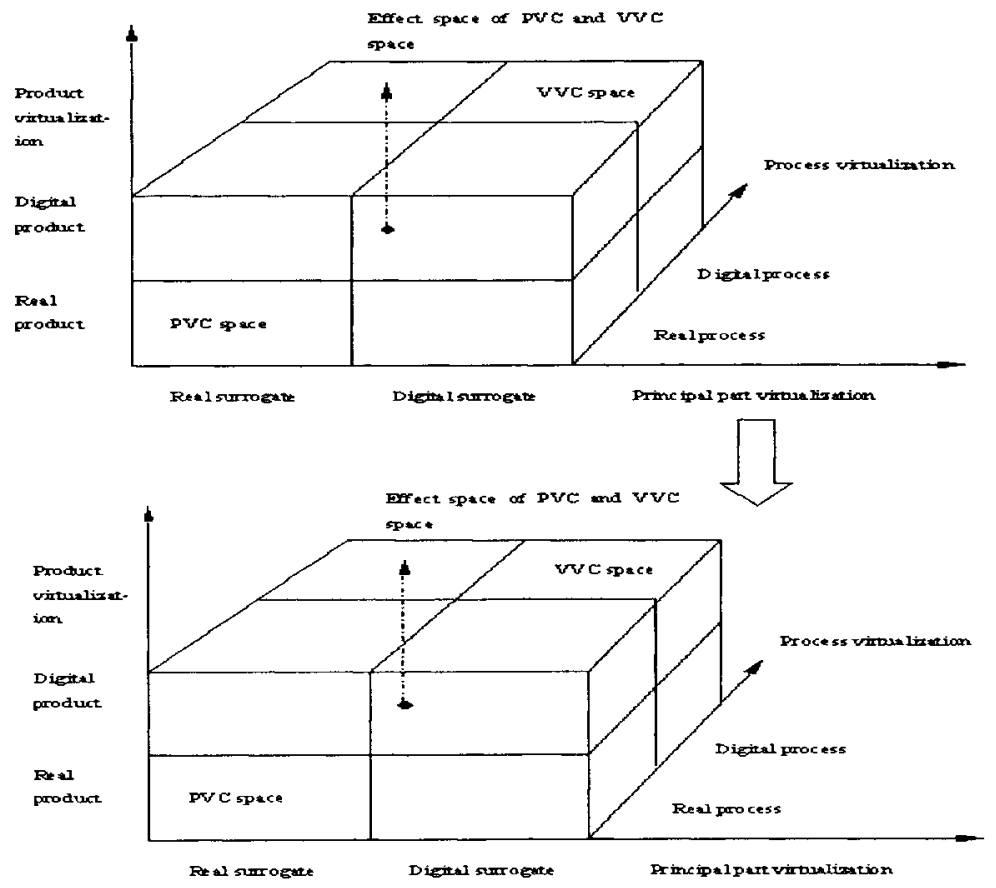




\subsection{Participant entity}

In virtual value chain, value is created using the contact between member, material provider, operator, and user, which is a participant entity in transfer from physical value chain to virtual value chain. Their relation can be described via cooperation-deal competition model (for example figure 4). The model is put forward based on five kinds of competition model with adding the competition model between cooperator and alliance, at the same time, equality and virtual characteristic of E-business enterprises is referred. The model analyzes the participants that correlate with enterprise such as provider, consumer, cooperator, alliance, competitor, invader, and replacer from three respects such as deal, cooperation, industry and so on. The cooperation deal tactic of virtual value chain transfer is established on the basis of cooperation-deal model.

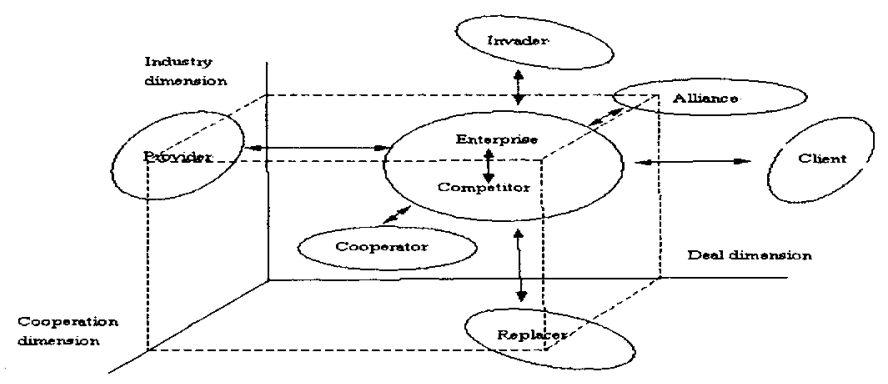

Fig.4 Cooperation-deal model in value chain transfer

\subsection{Transfer approach}

The basic rules of physical value chain are standardization, volume-produce, popularcommunication; however, that of virtual value chain are oriented client, one-to-one communication, it is a unification between produce system and communication system. In the process of transition, the builder must improve the flexibility of communication in order to form an efficient communication channel. The provider will alter the stratagem depends on standardization produce greatly, consider the individuation demand of clients, and improve the flexibility of produce and logistics. The operator must renovate constantly system to make product and communication meet the client oriented demand. The transfer approach can be expressed into figure 5 .

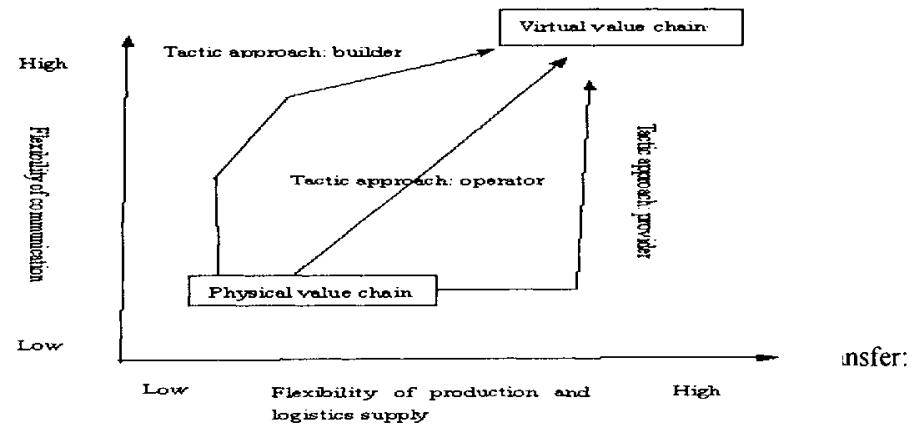


Builder; builder develops, organizes, manages all kinds of content and conception; and distributes them. Managing market efficiently, and integrating different provider chain using the least friction and the fastest velocity are its kernel craftsmanship, which increase the capability of value creation.

$>$ Provider; provider offers content, component, product, sub-system, user service and user instruments. They not only consider the builder as a distributor but also a virtual business entity.

$>$ Operator; the operator answers for the real commodity flow, and runs electronic information infrastructure and so forth.

$>$ User; user keeps contact with builder each other.

Builder, provider, operator and user can be modeled by multi-agent system. Beginning from inner value chain in enterprise, the value network is created by expending the cooperation-deal model; and then enterprise value network is depicted by adopting deal agent, cooperation agent, industry agent, core enterprise agent, which will form the model of enterprise value network.

\subsection{Simulation design of transfer approach}

The formalization define of trans-organization flow model (IPR-PN) in virtual value chain is formed by Petri network tool on the basis of enterprise value network model. Namely:

IPR- PN $=\{T, P, T O K E N$, LINK, PIN $\}$

Where IPR-PN is trans-organization flow, which is composed of four parts such as $\mathrm{T}, \mathrm{P}$, TOKEN, LINK; $\mathrm{T}=\{\mathrm{TI}, \mathrm{TO}, \mathrm{TF}\} ; \mathrm{T}$ is a transfer object in a Petri network, which is a set that holds the disposition of input resource and action of produce output. TI is an input object, which depicts the characteristic of input data. It includes one or more objects, which represent the business entity. TO is an output object that depicts the logistic relation of different action. $\mathrm{TF}$ is the operation of action, which describes the deal of input object. Because of hierarchy of flow, $T$ also denotes IPR $-P N$ in next hierarchy; as a result, $T$ holds two basic kinds: system and processor. $\mathrm{P}$ is position element in the Petri network. It denotes an occurrence or a field; at the same time, it also denotes resource in the field. PP denotes locale or event. $\mathrm{P}$ has two basic kinds: Channel and Store. Element T holds TI, TO, TF; and it and P form the network framework of flow. TOKEN is a set composed of all kinds of token. TOKEN holds enough information; it is an information carrier of flow model, which includes the involved factors that leads to change of flow. The factors include raw material, product, staff, tool, equipment, data and so on. When it flows in the network composed of element $T$ and $P$, TOKEN will change according to the rule. Optimization of flow is achieved by simulating approach of flow, the change of information, and tracking the operation. LINK is a mapping from abstract flux to sub-flow model, namely, LINK: System $\rightarrow$ IPR-PN. LINK forms the nexus between super stratum and underplayed model, which is a key element that can achieve the decomposition of hierarchy in the flow. In $\mathrm{P}$, has an especial element; it is the element $\mathrm{P}$ of input and output flow, which can relate different bottom flow. The object is called PIN, which includes three kinds; they are Inputpin, Outputpin, Storepin. PIN depicts the boundary relation, which is a key element to achieve integration of flow synchronously.

Sub-flow relation is established by element LINK. The relation between different flows is established via element PIN in same hierarchy. The simulation of transfer approach from physical value chain to virtual value chain can be achieved by IPR-PN model. 


\section{Conclusion and future development}

Value chain is a basic method and framework to understand enterprise behavior and guide competition conduct. In the B2B E-business, traditional value chain changes greatly under the influence of information technology, and the changes are analyzed in the paper. The connotation of virtual value chain in B2B E-business is represented, the similarities and differences of physical value chain and virtual value chain is compared, the transfer approach and steps from physical value chain to virtual value chain were investigated, which can provide the application of $\mathrm{B} 2 \mathrm{~B}$ E-business in an enterprises with novel ideal.

The model of value chain for enterprise study focus on function department, the process of resource flow is similar to the process of value increment in different department in enterprises. However, with the drastic development of global competition and the fast change of consumer demands, the management pattern that focus on occupation craftsmanship based on labor and specialization cooperation is facing serious challenge, separate deal can not create satisfactory value for consumer. Integrating all action orderly can create approving value for consumer. In B2B Ebusiness, enterprises need cooperation greatly. As a result, the recombination of trans-origination operation flow is necessary, which is a motif need be investigated in the further.

\section{References}

1. Michael. Porter. Competitive Advantage[ M]. Huaxia Publishing House, 1997;

2. Jeffrey F.Rayport \& John J.Sviokla. "Exploiting the Virtual Value Chain"[J].Harvard Business Review, Sep-Dec, 1995;

3. Prahalad.C.K.and HameI.G."The Core Competence of the orporation"[J].Harvard Business Review, 1990;

4. Q. Yang, X.T Wang \& S.J Hu. "Strategic Alliance---- New Ideas of Enterprise Development". Management Modernization, 2001, (1);

5. L. Chen, W.X Xu, T.X Liu. "On Economic Essence of Virtual Enterprises" [J]. Chinese Management Science, 2000, (11);

6. X.B Song, J.L Yu. "Technology Innovation\& Concept Innovation" [J]. Enterprise Management, 2001,(1);

7. S.G Wang. "Virtual Enterprises based on Global Supply Chain". Journal of Management Engineering, 1999, (5);

8. X.Y Chi. "Review of Value Chain Research\& Development"[J] . Foreign Economic\& Management, 2000, (1);

9. J.X Shen. "Value Chain Management Pattern of New Economic Era: Virtual\& Vertical Integration"[J]. NanJing Social Sciences, 2002, (11);

10. H.L Lan. "Analysis\& Acknowledgement of Core Specialty"[J]. Enterprise Management, $2000,(3)$;

11. R.H Lin , H.A Li. "Network Organization---- A New Organizational Model of More Environmental Adaptability"[J]. Nankai Management Review, 2000, (3). 